\title{
Risk of vertical transmission of chronic viral infections after invasive prenatal procedures
}

\author{
Brindusa Cimpoca ${ }^{1}$, Anca Maria Panaitescu ${ }^{1,2}{ }^{-}$, Nicolae Gica ${ }^{1,2}{ }^{-}$, \\ Alina Veduta ${ }^{1}{ }^{1}$, Anca Ciobanu ${ }^{1,2}$ \\ 'Gynaecology Department, Filantropia Clinical Hospital, Bucharest, Romania \\ 2Department of Obstetrics and Gynecology, Carol Davila" University of Medicine and Pharmacy, Bucharest, Romania
}

\begin{abstract}
Objectives: Invasive prenatal procedures including amniocentesis, chorionic villus sampling (CVS) can be prenatally indicated for diagnostic purposes. Chronic viral infections with Human Immunodeficiency Virus (HIV), Hepatitis C Virus (HCV), hepatitis B virus (HBV) are not uncommon in women of reproductive age.

The aim of this narrative literature review is to provide guidance on the best clinical practice in antenatal invasive testing and fetal surveillance in pregnancies with $\mathrm{HIV}, \mathrm{HCV}, \mathrm{HBV}$ and treponema pallidum infected women.

Material and methods: A review of the literature was conducted in the database of PubMed to select full-length articles published in peer-reviewed journals between 1990 and 2020. The keywords along with respective combinations included in the search strategy were invasive testing, prenatal diagnosis, amniocentesis, chorionic villus sampling, cordocentesis, fetoscopy, chronic viral infections, hepatitis B, hepatitis C, HIV, treponema pallidum, syphilis, vertical transmission, MTCT.

Results: For patients with hepatitis B infection, it is important to assess the HBeAg status and HBV DNA levels and for those patients with high viral load, antiviral therapy (Tenofovir) for a few weeks may be needed to reduce the viral load prior to the invasive procedure. In women positive for HCV, the viral load and HIV status should be assessed to establish the risk of vertical transmission; while for patients with HIV, highly active antiretroviral therapy administration and low viral load are predictive for reduced vertical transmission even after performing an invasive procedure. In all cases invasive procedure should be replaced by non-invasive prenatal testing if this is a feasible alternative and when invasive testing is indeed required, transplacental passage should be avoided.
\end{abstract}

Key words: invasive testing; vertical transmission; hepatitis $\mathrm{B}$; hepatitis $\mathrm{C}$; HIV; treponema pallidum

Ginekologia Polska 2022; 93, 3: 248-255

\section{INTRODUCTION}

Invasive prenatal procedures including amniocentesis, chorionic villus sampling (CVS), cordocentesis can be prenatally indicated for diagnosis or therapeutic purposes. The main concern related to invasive procedures in pregnancy is the risk of miscarriage or preterm birth, risk which was extensively studied in large observational studies [1]. Fetal medicine specialists should also be aware of other potential risks, such as possible increased rate of vertical transmission of chronic infections or isoimmunization in Rhesus negative patients. Therefore, pregnant women should be properly counselled before consenting for an invasive procedure. With the new development of more accurate screening methods, an invasive testing is nowadays offered with precaution. If in the past one of the main indications for performing an invasive testing was advanced maternal age, the non-invasive prenatal testing through cell-free DNA (cfDNA) has now replaced most of these unnecessary invasive procedures in high-risk patients based only on maternal age or previous history. Moreover, new technologies are being developed to screen general population for other genetic disorders besides the commonest chromosomal abnormalities. Single-gene diseases and fetal exome sequencing are the new target of cell free DNA technique, but the performance of such test in screening for such rare genetic disorders is yet to be established [2]. Currently, the most common indications for diagnostic invasive testing are abnormal screening test results [3], structural abnormalities identified by ultrasound, familial genetic disorders with recurrence risks, while for the therapeutic purpose, an invasive 
procedure is most frequently performed in cases of fetal anemia for intrauterine blood transfusion.

Chronic viral infections with Human Immunodeficiency Virus (HIV), hepatitis C virus (HCV), hepatitis B virus (HBV) are not uncommon in women of reproductive age and general efforts have been made to develop best strategies on how to manage pregnancy and delivery in these women to prevent vertical transmission and to reduce perinatal morbidity. Routine antenatal screening for maternal viral infections, antiviral treatment throughout pregnancy, early postpartum vaccination and immunoglobulin administration or neonatal treatment are current recommendations proven to be beneficial in reducing the mother-to-child-transmission (MTCT). In addition to these active therapeutic measures, avoiding some invasive procedures during pregnancy or delivery, procedures that might cause placental disruption, increasing the maternal-fetal blood contamination and thereby to possibly increasing viral transmission, has been considered protective. The real effect of invasive prenatal procedure on vertical transmission rate is not completely understood, but the potential risks derived from current data should not be ignored and should be discussed with the parents prior to an invasive testing.

The overall aim of this narrative literature review is to provide guidance on the best clinical practice in antenatal invasive testing and fetal surveillance in pregnancies with HIV, HCV, HBV or Treponema Pallidum infected women. Vertical transmission or MTCT defines the transmission of the virus from the mother to the unborn child during pregnancy, at the time of delivery, or during the first six weeks postpartum.

\section{MATERIAL AND METHODS}

A review of the literature was conducted in the database of PubMed, to select full-length articles published in peer-reviewed journals between 1990 and 2020. The keywords along with respective combinations included in the search strategy were invasive testing, prenatal diagnosis, amniocentesis, chorionic villus sampling, cordocentesis, fetoscopy, chronic viral infections, hepatitis B, hepatitis C, HIV, treponema pallidum, syphilis, vertical transmission, MTCT.

\section{Hepatitis B Virus}

Hepatitis B infection is a global health concern mostly because of its persistence as chronic infection and potential risk of hepatocellular carcinoma. The earlier the infection is acquired the higher the risk of persisting as chronic infection. Up to $90 \%$ of subjects infected perinatally may develop chronic infection and almost 30\% will end up developing cirrhosis, compared to a risk of less than $5 \%$ when infection occurs during adulthood [4]. Due to this risk, MTCT has been a recent subject of research to prevent or to reduce the risk of transmission during pregnancy and childbirth.

The introduction of Hepatitis B vaccine, a recombinant vaccine, has dramatically reduced the number of new cases of Hepatis B infection. More strategies are used to prevent MTCT of HBV infections, such as universal screening for maternal hepatitis $B$ infection (hepatitis $B$ surface antigen (HBsAg)) at booking; hepatitis B vaccination during pregnancy under specific circumstances (when the immunization series had begun before conception or a previously unvaccinated, uninfected pregnant women is at increased risk for acquiring the virus $[5,6]$; hepatitis $B$ immunoglobulin (HBIG 250IU) administrated to the neonate during the first 24 hours of life when the mother has HBV infection (second dose at 4 weeks of age) in addition to the universal vaccine $(8,12$ and 16 weeks of age). These have contributed to a reduction of 95 to $97 \%$ in MTCT rates [7]. Despite all these strategies, perinatal transmission still represents almost $50 \%$ of all new HBV infections.

Data regarding maternal-fetal transmission during pregnancy and delivery show that this risk is related to hepatitis $\mathrm{B}$ e-antigen ( $\mathrm{HBeAg}$ ) status. When positive it indicates that the virus is actively replicating and therefore the person is infectious and can cause vertical transmission. Low viral load (VL) of HBV DNA below $10^{7}$ copies $/ \mathrm{mL}$ (7.0 log 10 copies/MI) and additionally passive immunization at birth, maternal antiviral therapy during pregnancy can reduce the risk of transmission $[8,9]$.

There are contradictory data regarding the transmission risk after an invasive procedure. Most of the studies involved a small number of pregnancies, incomplete data regarding the DNA HBV viral load or concomitant HBeAg status or inappropriate postpartum follow up. The most likely route of transmission during an invasive procedure is by maternal fetal blood contamination or amniotic fluid contamination, transplacental procedures caring a significant higher risk of contamination [10]. Although very uncommon, other mechanism of intrauterine transmission has been recently described in the early stage of pregnancy via an infected male germline or maternal oocytes in the embryonic stage [11].

Contrary to what was previously reported, the latest data coming from the largest retrospective study involving 143 pregnancies positive for hepatitis $B$ undergoing amniocentesis between 16 and 35 weeks gestation, showed that an invasive procedure increases the MTCT risk in HBsAg-positive pregnant women, and viral load HBV DNA $\geq 10^{7}$ copies $/ \mathrm{mL}$ (7.0 $\log 10$ copies $/ \mathrm{mL}$ ). The MTCT rate was $2.5 \%$ in women who underwent amniocentesis vs $0.5 \%$ in patient without invasive procedure and all cases of vertical transmission were in patients $\mathrm{HBeAg}$ positive [12]. However, the results should be interpreted with caution, as the reported 
Table 1. Reviewed studies comparing the MTCT in pregnant women with chronic hepatitis B with and without the invasive procedure (amniocentesis) performed during pregnancy

\begin{tabular}{|c|c|c|c|c|c|}
\hline Study & Population (n) & $\mathrm{HBeAg}+$ & Viral load & MTCT with amniocentesis & MTCT without amniocentesis \\
\hline $\begin{array}{l}\text { Grosheide et al. } \\
1994 \text { [14] }\end{array}$ & 15 & 2 & Not reported & $0 \%$ & \\
\hline $\begin{array}{l}\text { Ko et al. } \\
1994[15]\end{array}$ & 67 & 19 & Not reported & $\begin{array}{c}1 / 35(2.9 \%) \text { at birth } \\
\mathbf{3 / 3 2}(\mathbf{9 . 4 \% )} \text { at } 3 \mathrm{~m}-5 \mathrm{y} \text { all in cases } \\
\text { with } \mathbf{H B e A g}+\end{array}$ & $\begin{array}{c}2 / 65(3.1 \%) \text { at birth } \\
379 / 3454(11 \%) \text { at } 3 \mathrm{~m}-5 \mathrm{y}\end{array}$ \\
\hline $\begin{array}{l}\text { Alexaner et al. } \\
1999[16]\end{array}$ & 21 & 1 & Not reported & $0 \%$ & \\
\hline $\begin{array}{l}\text { Towers et al. } \\
2001[17]\end{array}$ & 47 & Not reported & Not reported & $0 \%$ & \\
\hline $\begin{array}{l}\text { YiW et al. } \\
2014 \text { [10] }\end{array}$ & 63 & 22 & $\begin{array}{c}23>500 \mathrm{c} / \mathrm{mL} \\
6>7.0 \log 10 \mathrm{c} / \mathrm{mL}\end{array}$ & $\begin{array}{c}6.4 \% \\
50 \% \text { in high VL }\end{array}$ & $\begin{array}{c}2.5 \% \\
4.5 \% \text { in high VL }\end{array}$ \\
\hline $\begin{array}{l}\text { Han et al. } \\
2019[12]\end{array}$ & 143 & 49 & $37>7.0 \log 10 \mathrm{c} / \mathrm{mL}$ & $\begin{array}{c}11 / 143(7.7 \%) \text { at birth } \\
\mathbf{4}(\mathbf{2 . 8 \% )} \text { at } 7-12 \mathrm{~m} \text { all in } \mathbf{H B e A g}+\end{array}$ & $\begin{array}{c}34 / 605(5.6 \%) \text { at birth } \\
\mathbf{3}(\mathbf{0 . 5} \%) \text { at } 7-12 \mathrm{~m}\end{array}$ \\
\hline
\end{tabular}

$\mathrm{HBeAg}+$ - positive hepatitis B e-antigen; $\mathrm{c} / \mathrm{mL}$ — copies $/ \mathrm{mL} ; \mathrm{m}$ - months; $\mathrm{y}$ - years; $\mathrm{MTCT}$ - mother-to-child-transmission; VL — viral load

rate of vertical transmission in this cohort was much lower than previously shown in $\mathrm{HBeAg}$ positive patients where the MTCT rate is about $5-10 \%$ even in cases without an invasive procedure [13]. Moreover, the study results showed that antiviral therapy a few weeks prior to invasive testing (Tenofovir, Telbivuldine or Lamivudine) seems to reduce MTCT rates in mothers with high viral load (0\% vs 14\%) [12].

These data are consistent with a retrospective study from 2014 which also showed that although amniocentesis did not increase the risk of MTCT in the general cohort, it was significantly associated with a higher rate of vertical transmission in the subgroup of women with high HBV DNA levels, above $10^{7}$ copies $/ \mathrm{mL}$ ( $7.0 \log 10$ copies $/ \mathrm{mL}$ ), with a transmission rate of $50 \%$ in the group with amniocentesis vs. $4.5 \%$ in the non-invasive group. Placental position also appears to be an independent risk factor, as all infected infants in the amniocentesis group had an anterior placenta [10]. A summary of the studies is listed in Table 1.

These new results suggest that amniocentesis in women with hepatitis $\mathrm{B}, \mathrm{HBeAg}$ positive or with high viral load should be considered in highly selected cases when the suspected genetic conditions are beyond the current clinical applicability of non-invasive genetic testing and in those cases the antiviral therapy (Tenofovir) for a few weeks may be needed to reduce the viral load prior to the procedure [12]. Avoiding placenta is another important measure to reduce the risk of vertical transmission, therefore the invasive procedure in the first trimester through CVS should be postponed and replaced with second trimester testing through amniocentesis.

Currently there are no available studies to report on vertical transmission of HBV using other prenatal invasive procedures such as CVS, fetal blood sampling or therapeutic invasive procedures, therefore the risks and benefits of such procedures should be assessed and discussed with the parents prior to their clinical use.

Hepatitis B immunoprophylaxis failure occurs in $5-10 \%$ of infants of HBV-infected mothers HBeAg-positive, even without any invasive testing performed prenatally. Various factors have been reported in relation to immunoprophylaxis failure: earlier administration of immunoglobulin and first dose of vaccine within 1-2 hours after birth instead of first 12-24 h [18], HBV DNA levels, low birth weight or preterm infants. Administration of HBIG in the third trimester of pregnancy, vaginal delivery and breastfeeding did not seem to have a significant effect on HBV mother-to-infant transmission [19].

Prenatal fetal contamination as a cause of postnatal immunoprophylaxis failure has been studied through various fetal samples collected by prenatal invasive procedures, either of amniotic fluid, fetal blood sample or placental tissue to assess the fetal intrauterine status before labour and to determine if the passive-active immunoprophylaxis administered postpartum is ineffective due to early fetal intrauterine infection. In a study on more than 250 pregnant women with $\mathrm{HBsAg}$ positive invasive prenatal procedure was undertaken in 197 of cases of amniocentesis and 55 of cordocentesis. There were 92 women also positive for $\mathrm{HBeAg}$ and 146 had detectable levels of DNA HBV with a mean of $6.5 \log 10$ copies $/ \mathrm{mL}$ (3,162,278 copies/mL). Low levels of HBV DNA were found in 12 amniotic fluid samples and four blood samples and all 16 cases of HBV DNA-positive fetuses were limited to $\mathrm{HBeAg}$-positive mothers with viral loads higher than $10^{6}$ copies $/ \mathrm{mL}$. All neonates received the vaccine at birth and 198 were followed up at one year of life. Despite immunoprophylaxis, there were six children with persistent positive $\mathrm{HBsAg}$, all born to $\mathrm{HBeAg}$-positive mothers with high serous HBV DNA levels. Only one of them was found to be 
positive for intrauterine HBV DNA and three of them were found to be intrauterine $\mathrm{HBeAg}$ positive. The conclusion of the study was that prenatal intrauterine expression of HBV antigens and HBV DNA does not necessarily indicate postnatal HBV infection and vaccine failure [20]. Immature placenta might allow small quantities of soluble HBsAg and free HBV DNA leakage into the uterus, but the hepatocytes are fully developed later in the second half of pregnancy and only after that period are able to support viral replication and active infection, when binding sites for receptors encountered on $\mathrm{HBV}$ particles are present and mature enough on the surface of hepatocytes [21]. Therefore, most of the cases, although small amounts of virus are present in the blood or amniotic fluid, are effectively resolved after early vaccination in the first hours of life combined with immunoglobulin administration [21]. This might be also the explanation for the lower risk associated to invasive procedure in women with low viral load and HBeAg-negative.

\section{Hepatitis C Virus}

Hepatitis C has common transmission routes as HIV, and therefore it can be associated with HIV infection (co-infection). The mother to child transmission can occur during pregnancy, as has the same likelihood in all trimesters [22]. Usually, the risk of fetal infection is increased when there is active liver disease, when the viral load is higher than $10^{6} / \mathrm{mL}$ or in women co-infected with HIV. When viral load is less than $10^{5} \mathrm{HCV}$ RNA copies/mL [23] the chance of vertical transmission is lower, but not inexistent as there are reported cases with undetectable viremia during pregnancy and fetal transmission [24].

A recent systematic review quotes the risk of vertical transmission of $5 \%$ in women without HIV co-infection, increasing to $10 \%$ when HIV is associated [25].

There is limited data to address the potential risk of vertical transmission in women with HVC undergoing invasive testing and the current recommendations are based on small case series. In a study involving 22 women with hepatitis C, RNA positive detectable in serum in 16 of them, undergoing amniocentesis in the second trimester of pregnancy, there were no cases of neonatal infection [26]. Also, in a study on 161 cases of maternal HCV, amniocentesis did not appear to be an independent risk factor for increased rate of viral transmission [27].

Antenatal diagnostic invasive testing in HCV RNA-positive mothers with high VL could potentially increase the risk of fetal infection, although there is insufficient data [28]. Women undergoing amniocentesis or other invasive procedure should be counselled regarding the lack of data and potential risks which cannot be excluded.

According to American Association for the Study of Liver Disease (AASLD) and Infectious Disease Society of America
(IDSA) the most efficient strategy for reducing the risk of $\mathrm{HCV}$ transmission from mother to child is identifying and treating HCV-infected women before conception [29], as treatment during pregnancy is not recommended due to its teratogenicity.

\section{Human immunodeficiency Virus}

One major success in the management of HIV infected patients has been the prevention of mother to child transmission. The Paediatric AIDS Clinical Trials Group 076 demonstrated in 1994 that administering zidovudine in pregnancy and neonatal period could reduce the chance of vertical transmission by $70 \%$ [30]. During natural history of HIV in pregnancy, with no intervention, the risk of fetal infections is between 15 to $40 \%$ [31], depending on the presence of risk factors such as viral load, CD4 cell count, obstetrical factors like prematurity, premature rupture of membranes, intrapartum procedures, breastfeeding. In the early 2000, due to routine antenatal screening for HIV and initiation of treatment for at least two weeks with antiretroviral therapy (ART), mother to child transmission rate decreases to $0.5 \%$ in patients with $\mathrm{VL}<50 \mathrm{c} / \mathrm{mL}$ [31].

In 2015 the French national prospective multicenter Perinatal Cohort concluded that no mother to child transmission occurred in women on highly active antiretroviral therapy (HAART) before pregnancy who delivered with plasma $\mathrm{VL}<50 \mathrm{c} / \mathrm{mL}$ [32]. Inconsiderate of the plasma viral load, the mother to child transmission rate is $0.2 \%$ when HAART is commenced before conception, $0.4 \%$ in the first trimester, $0.9 \%$ in second trimester and $2.2 \%$ in the last trimester [32]. Therefore, viral suppression is critical to decrease the chance of HIV transmission to the unborn child. The longera woman is on ART during pregnancy, the better the outcomes due to an increased likelihood of an undetectable VL at delivery, thus preventing vertical transmission [32, 33]. An overview of the risk of mother to child transmission of HIV depending on the maternal status of the infection and viral load during different stages of pregnancy is provided in Table 2.

\section{Invasive testing in a high-risk pregnancy}

Whenever possible, cfDNA testing should be offered in high-risk pregnancies for aneuploidies, as in singleton pregnancies, the detection rate using cfDNA for trisomy 21 is $99.2 \%$, at a false positive rate of $0.09 \%$ [34]. If a prenatal invasive diagnostic test is being considered, the clinician must inform the parents regarding potential risks related to the procedure.

In the past, antenatal invasive testing or intrauterine procedures were routinely discouraged in HIV-infected pregnant women, due to increased risk of MTCT as puncture of the uterine wall, placenta or umbilical cord and eventually 
Table 2. The risk of mother to child transmission of HIV depending on the maternal status of the infection and viral load during different stages of pregnancy

\begin{tabular}{|l|c|}
\hline HIV positive pregnant patient & Risk of $\mathrm{MTCT}$ \\
\hline No treatment & $25 \%$ \\
\hline On ART with $\mathrm{VL}<50 \mathrm{c} / \mathrm{mL}$ before conception & $0.0 \%$ \\
\hline On ART before conception regardless $\mathrm{VL}$ & $0.2 \%$ \\
\hline On ART in $1^{\text {st }}$ trimester, regardless $\mathrm{VL}$ & $0.4 \%$ \\
\hline On ART in $2^{\text {nd }}$ trimester, regardless $\mathrm{VL}$ & $0.9 \%$ \\
\hline On ART in $3^{\text {rd }}$ trimester, regardless $\mathrm{VL}$ & $2.2 \%$ \\
\hline On ART with $\mathrm{VL}<50 \mathrm{c} / \mathrm{mL}$, regardless the start & $0.5 \%$ \\
\hline
\end{tabular}

ART - antiretroviral therapy; $\mathrm{c} / \mathrm{mL}$ - copies $/ \mathrm{mL}$; MTCT — mother-to-childtransmission, $\mathrm{VL}$ - viral load

lesions of the fetal skin may increase the chance of introducing maternal blood into fetal compartments, therefore increasing the risk of fetal HIV infection $[35,36]$.

In the new setting with highly active antiretroviral therapy (HAART) availability, the largest perinatal HIV cohort study does not show a significantly increased risk of MTCT when performing amniocentesis [36]. A tendency toward higher rates of vertical transmission was noted in the absence of treatment and with zidovudine alone, or combination of zidovudine and lamivudine [32].

According to the British HIV Association antenatal invasive testing should not be performed before the HIV status of the woman is known. In a HIV positive pregnant woman, ideally an invasive diagnostic procedure should be undertaken when viral load has been adequately suppressed to $<50 \mathrm{HIV}$ RNA copies/mL with combination of antiretroviral therapy (CART) [33]. If not on CART and the invasive testing cannot be postponed until viral suppression is achieved, the formal recommendation is that CART should be commenced to include altegravir $400 \mathrm{mg}$ two doses and a single dose of $200 \mathrm{mg}$ nevirapine to be administered $2-4$ hours before the Invasive procedure [34].

After the procedure, antenatal care should be continued as per local protocol and the frequency of antenatal visits should not be altered, unless there is a specific reason to do so. The reviewed studies comparing the mother to child transmission risk for HIV before and after initiation of highly active antiretroviral therapy are listed in Table 3.

\section{Treponema Pallidum infection - Congenital Syphilis}

Congenital syphilis (CS) can occur in any stage of maternal infection during pregnancy and can cause preterm birth, stillbirth or perinatal death. In the USA the rate of primary and secondary syphilis in women is increasing since 2014 and subsequently more cases of congenital syphilis, despite the World Health Organisation initiative to eliminate CS by 2015 [43].

Congenital syphilis occurs after transplacental passage of spirochetes in pregnant women who are untreated or inadequately treated, or at the time of delivery through contact with infectious maternal blood, secretions, or genital lesions, causing various clinical manifestations from stillbirth and neonatal death, cutaneous and visceral manifestations, to asymptomatic infection at birth. The risk of vertical transmission depends on gestational age (increasing with advancing gestation), on maternal infection stage and whether the treatment was initiated four weeks prior to delivery. MTCT is highest in untreated maternal primary or secondary syphilis with a rate of about $60-90 \%, 40 \%$ in early latent syphilis, and less than $10 \%$ in late latent syphilis [44, 45]. Early diagnosis and treatment in pregnancy significantly reduce those risks [46]. Aiming to reduce adverse pregnancy

Table 3. The reviewed studies comparing the mother to child transmission risk for HIV before and after initiation of highly active antiretroviral therapy

\begin{tabular}{|c|c|c|}
\hline Study & Invasive procedure & No invasive procedure \\
\hline \multicolumn{3}{|c|}{ Pre HAART } \\
\hline Mandelbrot et al. 1996 [39] & Amniocentesis, amnioscopy MTCT 36\% & MTCT $18 \%$ \\
\hline Tess et al. 1998 [40] & Amniocentesis in $3^{\text {rd }}$ trimester MTCT $\mathbf{4 0 \%}$ & MTCT $15 \%$ \\
\hline Mandelbrot et al. 2009 [37] & $\begin{array}{l}\text { No treatment MTCT } 25 \% \\
\text { Zidovudine MTCT } 6.1 \%\end{array}$ & $\begin{array}{l}\text { MTCT } 16 \% \\
\text { MTCT } 3.3 \%\end{array}$ \\
\hline \multicolumn{3}{|c|}{ Post HAART initiation } \\
\hline Floridia et al. 2016 [41] & $\begin{array}{l}75 \text { amniocentesis, } 12 \text { CVS } \\
\text { MTCT } \mathbf{2 . 3} \% \mathbf{( 2 / 8 8 )} \\
86 \text { negative - on HAART }\end{array}$ & \\
\hline Simoes et al. 2013 [42] & $\begin{array}{c}27 \text { amniocenteses, } 20 \text { on HAART } \\
\text { MTCT } 1 / 7 \text { (14\%) } \\
\text { from cases without HAART }\end{array}$ & \\
\hline Mandelbrot et al. 2009 [37] & MTCT 0\% on HAART & \\
\hline
\end{tabular}

HAART — highly active antiretroviral therapy; MTCT — mother-to-child transmission; CVS — chorionic villus sampling 
outcomes, routine screening is recommended in the first trimester of pregnancy and for high-risk women re-testing in the third trimester. Treatment in the first and second trimester has a greater impact in reducing the risk of perinatal adverse outcomes compared to treatment in the third trimester of pregnancy [47]. In a large retrospective study on more than 4000 syphilis infected pregnant women, it was showed that there were no cases of congenital syphilis in women who initiated treatment in the first trimester, while those who started the treatment in the third trimester had a higher risk of stillbirth, preterm birth and low birth weight neonates [48]. For a better neonatal outcome treatment should be initiated at least 30 days before delivery. The only efficient and recommended treatment of syphilis remains Benzathine Penicillin G (BPG) and continuous fetal monitoring is required once the treatment is initiated to evaluate for the Jarisch-Herxheimer reaction, an acute inflammatory response which can cause preterm labor and fetal distress and appears in almost $50 \%$ of cases [49-51].

The fetal infection can be prenatally suspected after 18 weeks gestation when the fetus is able to produce an immunologic response with new onset ultrasound signs. The most common are hepatomegaly, placentomegaly, polyhydramnios, fetal anemia, ascites, hydrops, or cardiomegaly. Although signs of fetal infection will manifest in utero after 18 weeks gestation in almost $30 \%$ of infected untreated women, in $12 \%$ of cases the congenital infection is not prenatally detected, and the signs are evident only after birth [49].In neonates, syphilis infection can be asymptomatic in up to two-thirds of cases and if it remains recognised and untreated, in $40-60 \%$ of the cases there will be long term sequelae such as Hutchinson's teeth, interstitial keratitis, eighth-nerve deafness, neurodevelopmental delay.

Invasive procedure through amniocentesis and fetal blood sampling are performed in cases with suspected fetal syphilis for diagnosis (amniotic fluid detection of treponema pallidum) and for therapeutic purpose $[52,53]$. The main haematologic abnormalities in congenital syphilis are fetal anemia, thrombocytopenia, leukopenia, which also determine some of the ultrasound findings [54]. Intrauterine fetal blood transfusion by cordocentesis to correct fetal anemia might be indicated at early gestational ages when delivery is not an option, in addition to high doses of benzathine penicillin intravenously [55].

Invasive procedure for genetic testing in women with syphilis has not been studied as an independent risk factor for vertical transmission, being a method for diagnosis in cases of suspected fetal infection or it might be indicated as a therapeutic option.

However, with early detection and appropriate maternal treatment, invasive procedure did not seem to increase the risk of MTCT. This is supported by the results of a study involving 11 pregnancies, six women with secondary syphilis and five with latent syphilis. All cases had normal ultrasound examination and amniocentesis was performed before 20 weeks gestation in order to determine the rate of vertical transmission and to show that transplacental transmission can occur before 18 weeks. Amniotic fluid collected was analysed and treponema pallidum was present in four cases (36\%). After adequate maternal treatment with benzathine penicillin $\mathrm{G}$ started before 20 weeks gestation, all neonates were seronegative at delivery or at follow-up by $6-12$ months of age [53].

\section{CONCLUSIONS}

Based on currently available data, fetal medicine specialists should be aware of the patient's infectious status before performing an invasive procedure. For patients with hepatitis B infection, it is important to know the HBeAg-status and HBV DNA levels and for those patients with high viral load, antiviral therapy (Tenofovir) for a few weeks may be needed to reduce the viral load prior to the invasive procedure.

In women positive for HCV, the viral load and HIV status should be assessed to establish the risk of vertical transmission; while for patients with HIV, highly active antiretroviral therapy administration and low viral load are predictive for reduced vertical transmission even after performing an invasive procedure. In all cases invasive procedure should be replaced by non-invasive prenatal testing if this is a feasible alternative and when invasive testing is indeed required, transplacental passage should be avoided. Figure 1 gives an overview of the risk factors, rate of vertical transmission after invasive procedure and preventive measures in chronic viral infections. There is a need to better understand these risks and further research should be directed towards this task.

\section{Funding}

This research did not receive any specific grant from funding agencies in the public, commercial, or not-for-profit sectors.

\section{Conflict of interest}

None. 


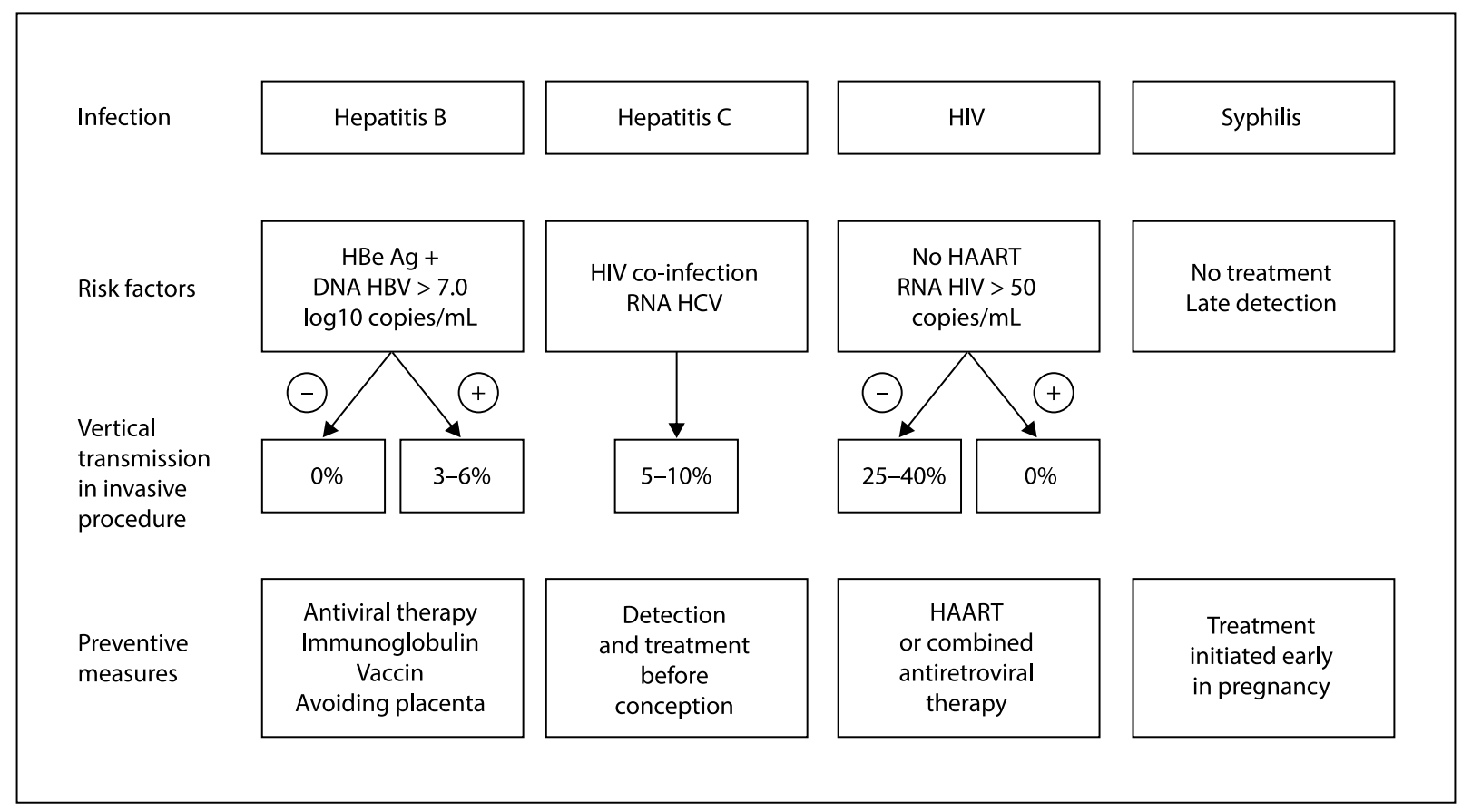

Figure 1. Risk factors, rate of vertical transmission after invasive procedure and preventive measures in chronic viral infections

\section{REFERENCES}

1. Salomon LJ, Sotiriadis A, Wulff CB, et al. Risk of miscarriage following amniocentesis or chorionic villus sampling: systematic review of literature and updated meta-analysis. Ultrasound Obstet Gynecol. 2019; 54(4): 442-451, doi: 10.1002/uog.20353, indexed in Pubmed: 31124209.

2. Hayward J, Chitty LS. Beyond screening for chromosomal abnormalities: Advances in non-invasive diagnosis of single gene disorders and fetal exome sequencing. Semin Fetal Neonatal Med. 2018; 23(2): 94-101, doi: 10.1016/j.siny.2017.12.002, indexed in Pubmed: 29305293.

3. Veduta A, Vayna AM, Duta S, et al. The first trimester combined test for aneuploidies - a single center experience. J Matern Fetal Neonatal Med. 2018;31(16): 2091-2096, doi: 10.1080/14767058.2017.1336220, indexed in Pubmed: 28553771.

4. Fattovich G, Bortolotti F, Donato F. Natural history of chronic hepatitis B: special emphasis on disease progression and prognostic factors. J Hepatol. 2008; 48(2): 335-352, doi: 10.1016/j.jhep.2007.11.011, indexed in Pubmed: 18096267.

5. American College of Obstetricians and Gynecologists. ACOG Practice Bulletin No. 86: Viral hepatitis in pregnancy. Obstet Gynecol. 2007; 110(4): 941-956, doi: 10.1097/01.AOG.0000263930.28382.2a, indexed in Pubmed: 17906043.

6. Ciobanu AM, Dumitru AE, Gica N, et al. Benefits and risks of IgG transplacental transfer. Diagnostics (Basel). 2020; 10(8), doi: 10.3390/diagnostics 10080583, indexed in Pubmed: 32806663.

7. Yi $\mathrm{P}$, Chen $\mathrm{R}$, Huang $\mathrm{Y}$, et al. Management of mother-to-child transmission of hepatitis B virus: Propositions and challenges. J Clin Virol. 2016; 77: 32-39, doi: 10.1016/j.jcv.2016.02.003, indexed in Pubmed: 26895227.

8. Baciu I, Domuncu DA, Domuncu T. Tenofovir disoproxil fumarate for preventing mother-to-child transmission of hepatitis $b$ : a literature review. Clinical and Experimental Obstetrics \& Gynecology. 2021; 48(1): 9, doi: 10.31083/j.ceog.2021.01.2240.

9. Pan CQ, Duan Z, Dai E, et al. China Study Group for the Mother-to-Child Transmission of Hepatitis B. Tenofovir to prevent Hepatitis B transmission in mothers with high viral load. N Engl J Med. 2016; 374(24): 2324-2334, doi: 10.1056/NEJMoa1508660, indexed in Pubmed: 27305192.

10. Yi W, Pan CQ, Hao J, et al. Risk of vertical transmission of hepatitis $B$ after amniocentesis in HBs antigen-positive mothers. J Hepatol. 2014; 60(3): 523-529, doi: 10.1016/j.jhep.2013.11.008, indexed in Pubmed: 24269471.

11. Wang S, Peng G, Li M, et al. Identification of hepatitis B virus vertical transmission from father to fetus by direct sequencing. Southeast Asian JTrop Med Public Health. 2003; 34(1): 106-113, indexed in Pubmed: 12971522.
12. Han Z, Zhang $Y$, Hou H, et al. Mother-to-child transmission of hepatitis $B$ virus after amniocentesis: A retrospective matched cohort study. Prenat Diagn. 2019; 39(6): 431-440, doi: 10.1002/pd.5452, indexed in Pubmed: 30916399.

13. Lou H, Zhou YH. Comment on "Mother-to-child transmission of hepatitis $B$ virus after amniocentesis: A retrospective matched cohort study". Prenat Diagn. 2019; 39(13): 1298-1299, doi: 10.1002/pd.5570, indexed in Pubmed: 31646660.

14. Grosheide PM, Quartero HW, Schalm SW, et al. Early invasive prenatal diagnosis in HBsAg-positive women. Prenat Diagn. 1994; 14(7): 553-558, doi: 10.1002/pd.1970140707, indexed in Pubmed: 7971756.

15. Ko TM, Tseng LH, Chang MH, et al. Amniocentesis in mothers who are hepatitis $B$ virus carriers does not expose the infant to an increased risk of hepatitis B virus infection. Arch Gynecol Obstet. 1994; 255(1): 25-30, doi: 10.1007/BF02390671, indexed in Pubmed: 8042875.

16. Alexander J, Ramus R, Jackson $G$, et al. Risk of hepatitis B transmission after amniocentesis in chronic hepatitis B carriers. Infectious Diseases in Obstetrics and Gynecology. 1999; 7(6): 283-286, doi: 10.1002/(sici)1 098-0997(1999)7:6<283::aid-idog6>3.0.co;2-t.

17. Towers CV, Asrat T, Rumney P. The presence of hepatitis B surface antigen and deoxyribonucleic acid in amniotic fluid and cord blood. Am J Obstet Gynecol. 2001; 184(7): 1514-8; discussion 1518, doi: 10.1067/mob.2001.114866, indexed in Pubmed: 11408875.

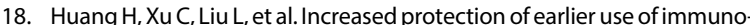
prophylaxis in preventing perinatal transmission of hepatitis B virus. Clin Infect Dis. 2020 [Epub ahead of print], doi: 10.1093/cid/ciaa898, indexed in Pubmed: 32634824.

19. Zhang L, Gui $X$, Wang Bo, et al. A study of immunoprophylaxis failure and risk factors of hepatitis B virus mother-to-infant transmission. Eur J Pediatr. 2014; 173(9): 1161-1168, doi: 10.1007/s00431-014-2305-7, indexed in Pubmed: 24699981.

20. Zhu YY, Mao YZ, Wu WL, et al. Does hepatitis B virus prenatal transmission result in postnatal immunoprophylaxis failure? Clin Vaccine Immunol. 2010; 17(12): 1836-1841, doi: 10.1128/CVI.00168-10, indexed in Pubmed: 20943880.

21. Bakkum B. The developing human: clinically oriented embryology, 7th ed. Journal of Manipulative and Physiological Therapeutics. 2003; 26(8): 536, doi: 10.1016/s0161-4754(03)00102-7.

22. Dibba $P, C$ Cholankeril $R$, Li AA, et al. Hepatitis C in pregnancy. Diseases. 2018; 6(2), doi: 10.3390/diseases6020031, indexed in Pubmed: 29702563. 
23. Indolfi $G$, Resti $M$, Indolfi $G$, et al. Intrafamilial transmission of hepatitis $C$ virus: infection of the father predicts the risk of perinatal transmission. J Med Virol. 2008; 80(11): 1907-1911, doi: 10.1002/jmv.21316, indexed in Pubmed: 18814243.

24. Tovo PA, Calitri C, Scolfaro $C$, et al. Vertically acquired hepatitis $C$ virus infection: Correlates of transmission and disease progression. World J Gastroenterol. 2016; 22(4): 1382-1392, doi: 10.3748/wjg.v22.i4.1382, indexed in Pubmed: 26819507.

25. Benova L, Mohamoud YA, Calvert C, et al. Vertical transmission of hepatitis C virus: systematic review and meta-analysis. Clin Infect Dis. 2014; 59(6): 765-773, doi: 10.1093/cid/ciu447, indexed in Pubmed: 24928290.

26. Delamare C, Carbonne B, Heim N, et al. Detection of hepatitis $C$ virus RNA (HCV RNA) in amniotic fluid: a prospective study. J Hepatol. 1999; 31(3):416420, doi: 10.1016/s0168-8278(99)80031-2, indexed in Pubmed: 10488698.

27. Poiraud S, Tenon H, Cohen J, et al. Mother to child transmission of hepatitis $C$ virus: A case-control study of risk factors. Gastroenterology. 2001; 120(5): A366, doi: 10.1016/s0016-5085(08)81818-5.

28. Gagnon A, Davies G, Wilson RD, et al. GENETICS COMMITTEE. Prenatal invasive procedures in women with hepatitis $B$, hepatitis $C$, and/or human immunodeficiency virus infections. J Obstet Gynaecol Can. 2014; 36(7): 648-653, doi: 10.1016/S1701-2163(15)30546-6, indexed in Pubmed: 25184985.

29. HCV Guidance: Recommendations for Testing, Managing, and Treating Hepatitis C. www.HCVGuidance.org.

30. Connor E, Sperling R, Gelber R, et al. Reduction of maternal-infant transmission of human immunodeficiency virus type I with zidovudine treatment. Studies in Family Planning. 1994; 25(6):373, doi: 10.2307/2137882.

31. Townsend $\mathrm{CL}$, Cortina-Borja $\mathrm{M}$, Peckham $\mathrm{CS}$, et al. Low rates of mother-to-child transmission of HIV following effective pregnancy interventions in the United Kingdom and Ireland, 2000-2006. AIDS. 2008; 22(8): 973-981, doi: 10.1097/QAD.0b013e3282f9b67a, indexed in Pubmed: 18453857.

32. Mandelbrot L, Tubiana R, Le Chenadec J, et al. ANRS-EPF Study Group. No perinatal HIV-1 transmission from women with effective antiretroviral therapy starting before conception. Clin Infect Dis. 2015; 61(11): 1715-1725, doi: 10.1093/cid/civ578, indexed in Pubmed: 26197844.

33. Read PJ, Mandalia S, Khan P, et al. London HIV Perinatal Research Group. When should HAART be initiated in pregnancy to achieve an undetectable HIV viral load by delivery? AIDS. 2012; 26(9): 1095-1103, doi: 10.1097/QAD.0b013e3283536a6c, indexed in Pubmed: 22441248.

34. Gil MM, Quezada MS, Revello R, et al. Analysis of cell-free DNA in maternal blood in screening for fetal aneuploidies: updated meta-analysis. Ultrasound Obstet Gynecol. 2015; 45(3): 249-266, doi: 10.1002/uog.14791, indexed in Pubmed: 25639627.

35. Giorlandino C, Gambuzza G, D'Alessio P, et al. Blood contamination of amniotic fluid after amniocentesis in relationto placental location. Prenatal Diagnosis. 1996; 16(2): 180-182, doi: 10.1002/(sici)1097-0223( 199602) 16:2<180::aid-pd833>3.0.co;2-b, indexed in Pubmed: 8650131.

36. Winsor $E$, Silver $M$, Theve $R$, et al. ternal cellcontamination in uncultured amniotic fluid. Prenatal Diagnosis. 1996; 16(1): 49-54, doi: 10.1002/(sici )1097-0223(199601)16:1<49::aid-pd808>3.0.co;2-u.

37. Mandelbrot L, Jasseron C, Ekoukou D, et al. ANRS French Perinatal Cohort (EPF). Amniocentesis and mother-to-child human immunodeficiency virus transmission in the Agence Nationale de Recherches sur le SIDA et les Hépatites Virales French Perinatal Cohort. Am J Obstet Gynecol. 2009; 200(2): 160.e1-160.e9, doi: 10.1016/j.ajog.2008.08.049, indexed in Pubmed: 18986640.

38. BHIVA Writing Group. BHIVA guidelines for the management of HIV in pregnancy and postpartum 2018.

39. Mandelbrot L, Mayaux MJ, Bongain A, et al. Obstetric factors and mother-to-child transmission of human immunodeficiency virus type 1: the French perinatal cohorts. SEROGEST French Pediatric HIV Infec- tion Study Group. Am J Obstet Gynecol. 1996; 175(3 Pt 1): 661-667, doi: 10.1053/ob.1996.v175.a75478, indexed in Pubmed: 8828431.

40. Tess $B H$, Rodrigues $L C$, Newell ML, et al. Breastfeeding, genetic, obstetric and other risk factors associated with mother-to-child transmission of HIV-1 in Sao Paulo State, Brazil. Sao Paulo Collaborative Study for Vertical Transmission of HIV-1. AIDS. 1998; 12(5): 513-520, doi: 10.1097/00002030-199805000-00013, indexed in Pubmed: 9543450.

41. Floridia M, Masuelli G, Meloni A, et al. Italian Group on Surveillance on Antiretroviral Treatment in Pregnancy. Amniocentesis and chorionic villus sampling in HIV-infected pregnant women: a multicentre case series. BJOG. 2017; 124(8): 1218-1223, doi: 10.1111/1471-0528.14183, indexed in Pubmed: 27319948.

42. Simões $\mathrm{M}$, Marques $\mathrm{C}$, Gonçalves $\mathrm{A}$, et al. Amniocentesis in HIV pregnant women: 16 years of experience. Infect Dis Obstet Gynecol. 2013; 2013: 914272, doi: 10.1155/2013/914272, indexed in Pubmed: 23970821.

43. World Health Organization. The global elimination of congenital syphilis: rationale and strategy for action. https://www.who.int/reproductivehealth/publications/rtis/9789241595858/en/.

44. Braccio S, Sharland M, Ladhani SN. Prevention and treatment of mother-to-child transmission of syphilis. Curr Opin Infect Dis. 2016; 29(3): 268-274, doi: 10.1097/QCO.0000000000000270, indexed in Pubmed: 27078816 .

45. Gomez GB, Kamb ML, Newman LM, et al. Untreated maternal syphilis and adverse outcomes of pregnancy: a systematic review and meta-analysis. Bull World Health Organ. 2013; 91 (3): 217-226, doi: 10.2471/BLT.12.107623, indexed in Pubmed: 23476094.

46. Hawkes S, Matin N, Broutet N, et al. Effectiveness of interventions to improve screening for syphilis in pregnancy: a systematic review and meta-analysis. The Lancet Infectious Diseases. 2011; 11(9): 684-691, doi: 10.1016/s1473-3099(11)70104-9.

47. Hawkes SJ, Gomez GB, Broutet N. Early antenatal care: does it make a difference to outcomes of pregnancy associated with syphilis? A systematic review and meta-analysis. PLoS One. 2013; 8(2): e56713, doi: 10.1371/journal.pone.0056713, indexed in Pubmed: 23468875.

48. Wan Z, Zhang $\mathrm{H}$, Xu H, et al. Maternal syphilis treatment and pregnancy outcomes: a retrospective study in Jiangxi Province, China. BMC Pregnancy Childbirth. 2020; 20(1): 648, doi: 10.1186/s12884-020-03314-y, indexed in Pubmed: 33109116.

49. Rac MWF, Stafford IA, Eppes CS. Congenital syphilis: A contemporary update on an ancient disease. Prenat Diagn. 2020; 40(13): 1703-1714, doi: 10.1002/pd.5728, indexed in Pubmed: 32362058.

50. Klein VR, Cox SM, Mitchell MD, et al. The Jarisch-Herxheimer reaction complicating syphilotherapy in pregnancy. Obstet Gynecol. 1990; 75: 375-80.

51. Myles TD, Elam G, Park-Hwang E, et al. The Jarisch-Herxheimer reaction and fetal monitoring changes in pregnant women treated for syphilis. Obstet Gynecol. 1998; 92(5): 859-864, doi: 10.1016/s00297844(98)00271-3, indexed in Pubmed: 9794683.

52. Wendel GD, Maberry MC, Christmas JT, et al. Examination of amniotic fluid in diagnosing congenital syphilis with fetal death. Obstet Gynecol. 1989; 74(6): 967-970, indexed in Pubmed: 2685682.

53. Nathan L, Bohman VR, Sanchez PJ, et al. In utero infection with Treponema pallidum in early pregnancy. Prenat Diagn. 1997; 17(2): 119-123, doi: 10.1002/(sici)1097-0223(199702)17:2<119::aid-pd39>3.0.co;2-t, indexed in Pubmed: 9061759.

54. Hollier LM, Harstad TW, Sanchez PJ, et al. Fetal syphilis: clinical and laboratory characteristics. Obstet Gynecol. 2001; 97(6): 947-953, doi: 10.1016/s0029-7844(01)01367-9, indexed in Pubmed: 11384701.

55. Chen I, Chandra S, Singh A, et al. Successful outcome with intrauterine transfusion in non-immune hydrops fetalis secondary to congenital syphilis. J Obstet Gynaecol Can. 2010; 32(9): 861-865, doi: 10.1016/S1701-2163(16)34658-8, indexed in Pubmed: 21050519. 